\title{
Screening of Lactic Acid Bacteria for the Bio-Control of Botrytis cinerea and the Potential of Lactiplantibacillus plantarum for Eco-Friendly Preservation of Fresh-Cut Kiwifruit
}

\author{
Nicola De Simone ${ }^{1}$, Vittorio Capozzi ${ }^{2}{ }^{\oplus}$, Maria Lucia Valeria de Chiara ${ }^{1}$, Maria Luisa Amodio ${ }^{1}$, Samira Brahimi ${ }^{3}$, \\ Giancarlo Colelli ${ }^{1}$, Djamel Drider ${ }^{4}{ }^{\circledR}$, Giuseppe Spano ${ }^{1}$ and Pasquale Russo ${ }^{1, *}$ \\ 1 Department of Agriculture, Food, Natural Science, Engineering, University of Foggia, Via Napoli 25, \\ 71122 Foggia, Italy; nicola.desimone@unifg.it (N.D.S.); m.dechiara@unifg.it (M.L.V.d.C.); \\ marialuisa.amodio@unifg.it (M.L.A.); giancarlo.colelli@unifg.it (G.C.); giuseppe.spano@unifg.it (G.S.) \\ 2 Institute of Sciences of Food Production, National Research Council of Italy (CNR), c/o CS-DAT, \\ Via Michele Protano, 71121 Foggia, Italy; vittorio.capozzi@ispa.cnr.it \\ 3 Laboratory of Applied Microbiology, Department of Biology, Faculty of Natural Sciences and Life, \\ University of Oran 1 Ahmed Ben Bella, Bp1524 El M' Naouer, Oran 31000, Algeria; sam90.brahimi@gmail.com \\ 4 UMR Transfrontalière BioEcoAgro1158, Univ. Lille, INRAE, Univ. Liège, UPJV, YNCREA, Univ. Artois, \\ Univ. Littoral Côte D’Opale, ICV-Institut Charles Viollette, 59000 Lille, France; djamel.drider@univ-lille.fr \\ * Correspondence: pasquale.russo@unifg.it
}

Citation: De Simone, N.; Capozzi, V.; de Chiara, M.L.V.; Amodio, M.L.; Brahimi, S.; Colelli, G.; Drider, D.; Spano, G.; Russo, P. Screening of Lactic Acid Bacteria for the Bio-Control of Botrytis cinerea and the Potential of Lactiplantibacillus plantarum for Eco-Friendly Preservation of Fresh-Cut Kiwifruit. Microorganisms 2021, 9, 773. https://doi.org/10.3390/

microorganisms 9040773

Academic Editor: Maurizio Cian

Received: 3 March 2021

Accepted: 2 April 2021

Published: 7 April 2021

Publisher's Note: MDPI stays neutral with regard to jurisdictional claims in published maps and institutional affiliations.

Copyright: (c) 2021 by the authors. Licensee MDPI, Basel, Switzerland. This article is an open access article distributed under the terms and conditions of the Creative Commons Attribution (CC BY) license (https:// creativecommons.org/licenses/by/ $4.0 /)$.
Abstract: Botrytis cinerea, responsible for grey mold, represents the first biological cause of fruit and vegetable spoilage phenomena in post-harvest. Kiwifruit is a climacteric fruit particularly prone to this mold infestation during storage. Lactic acid bacteria (LAB) are food-grade bacteria that can synthesize several metabolites with antimicrobial activity and are, therefore, suggested as promising and eco-friendly resources for the bio-control of molds on fruits and vegetables. In this work, we propose the screening of a collection of 300 LAB previously isolated from traditional sourdoughs for their ability to counteract in vitro the growth of Botrytis cinerea CECT 20973. Only $2 \%$ of tested LAB strains belonging to Lactiplantibacillus plantarum species, exerted a strong antagonism against $B$. cinerea. The cell-free supernatants were partially characterized and results clearly indicated that high levels of lactic acid contributed to the antagonistic activity. PAN01 and UFG 121 cell-free supernatants were investigated as potential bio-control agents in a preliminary in vivo assay using freshly cut kiwifruits as a food model. The application of cell-free supernatants allowed to delay the growth of $B$. cinerea on artificially contaminated kiwifruits until two weeks. The antagonistic activity was greatly affected by the storage temperature $\left(25^{\circ} \mathrm{C}\right.$ and $\left.4{ }^{\circ} \mathrm{C}\right)$ selected for the processed fruits, suggesting the importance to include microbial-based solution in a broader framework of hurdle technologies.

Keywords: Botrytis cinerea; post-harvest; kiwifruit; lactic acid bacteria; antifungal activity; biocontrol; sustainability

\section{Introduction}

Consumers highly appreciate kiwifruit for its sour and sweet taste, but also for its associated healthy features, attributed to high levels of vitamin C, flavonoids, minerals, and significant amounts of chlorophyll and carotenoids. Its consumption, as part of a balanced diet, has been reported to have multiple benefits (other than the nutritional ones), such as antioxidant capacity [1], an increase of HDL cholesterol and decrease of triglycerides [2], protection from oxidative stress [3], and favorable changes in the human colonic microbial community [4]. In addition, it is a crop with high economic relevance, with about four million tons produced worldwide in 2017, and approximately 1.5 million tons exported among countries [5]. The most important world kiwifruit producers are 
China, Italy, New Zealand, Chile, and Greece, representing more than $85 \%$ of the global production [1].

Kiwifruit is a climacteric fruit that can be stored for several months if harvested at physiological maturity. Recommended conditions include storage temperature of $0{ }^{\circ} \mathrm{C}$, relative humidity higher than $90 \%$ and atmosphere modification with 1 to $2 \% \mathrm{O}_{2}$ and 3 to $5 \% \mathrm{CO}_{2}$. Removal of ethylene from the storage atmosphere is also crucial [6]. Limiting factors for long-term storage is the loss of firmness due to ripening, especially in presence of ethylene, even at very low concentrations, and development of fungal decay. Removal of ethylene from storage rooms using ethylene scrubbers is highly recommended, but also treatment with 1-methylcyclopropene, a powerful inhibitor of its action, is very effective in slowing down fruit softening [7].

Among spoilage microorganisms, filamentous fungi are well-known to affect a wide range of fruits commodities, leading to significant economic losses and food wastes. Furthermore, they are considered as allergens, and they could produce mycotoxins, posing a critical concern for the safety of the consumers [8]. Botrytis cinerea, the grey mold's etiological agent, is a typical contaminant of a wide range of fruits and vegetables, with high relevance in terms of economic impact [9]. In particular, B. cinerea is the primary filamentous fungus responsible for the decay of kiwifruits [10], causing dark green color, water-soaked and soft texture on diseased tissues [11]. Although several methods are reported for the bio-control of grey mold in other commodities [12], only a few data are available for kiwifruits. Indeed, this disease is mainly controlled in the field and in the cold room by using synthetic fungicides. However, the appearance of fungicides-resistant strains [13], and the growing consumers demand for residue-free products has encouraged producers to adopt integrated management of post-harvest grey mold on fruit crops [14].

In recent years, with the aim to provide eco-friendly and safer approaches for the control of undesired microflora in food commodities, the use of microbial-based solutions is increasing [15]. Among these, the employment of Lactic Acid Bacteria (LAB) capable of inhibiting spoilage microorganisms can be a preferable choice because of the long history of safe use testified by the status of "generally recognized as safe" (GRAS) and "qualified presumption of safety" (QPS) [16]. Since LAB can be deliberately added into the food chains, in the last years, several studies suggested the use of LAB with antimicrobial properties as natural food preservatives against the development of spoilage fungi $[17,18]$. Their activity is expressed both through the competition for fundamental nutrients, and as a result of the synthesis of active compounds, such as organic acids, carbon dioxide, ethanol, hydrogen peroxide, fatty acids, acetoin, diacetyl, cyclic dipeptides, bacteriocins, or bacteriocin-like inhibitory substances $[17,19]$. Nevertheless, synergistic mechanisms among different metabolites have been reported to increase the overall antimicrobial activity substantially [20]. In addition, the availability of new analytical approaches is facilitating the purification and the characterization of new preservative compounds [21]. For these reasons, the discovery of new antifungal molecules and the understanding of the molecular basis of microbial interactions are receiving growing effort by the researchers.

In the fresh-cut sector, epiphytic bacteria and/or food-grade LAB strains have been proposed for the biocontrol of foodborne pathogenic bacteria (i.e., Salmonella spp., Escherichia coli O157:H7, and Listeria monocytogenes) [22,23], while molds are mainly controlled with physicochemical approaches [24], or the addition of bioactive polyphenols [25,26]. In a recent work, two strains of Lactiplantibacillus plantarum have been incorporated into a Konjac-based edible coating in order to prevent the growth of naturally occurring mold and yeast [27], suggesting the potential of this microbial species as biocontrol agent.

However, to the best of our knowledge, no studies report on the use of microbial metabolites produced from LAB for the bio-control of kiwifruits. For this reason, this work aims (i) to select LAB strains capable of inhibiting Botrytis cinerea; (ii) to partially characterize the active compounds responsible for the antifungal activity; and (iii) to assess the in vivo activity by using freshly cut kiwifruits as fruit model. 


\section{Materials and Methods}

\subsection{Microbial Strains and Growth Conditions}

Three-hundred LAB strains previously isolated from five different artisanal sourdoughs $[18,28]$, and available at the culture collection of the Industrial Microbiology Laboratory of the University of Foggia, were routinely cultured in MRS broth (Oxoid, Basingstoke, UK) at $30^{\circ} \mathrm{C}$.

Botrytis cinerea CECT 20973 was obtained by the Spanish Type Culture Collection (CECT, Paterna, Spain), and utilized as target spoilage strain in the screening assay. Lyophilized culture was re-suspended on saline solution $(0.9 \% \mathrm{NaCl})$, plated on Potato Dextrose Agar (PDA, Oxoid), and incubated at $25^{\circ} \mathrm{C}$ for 5 days. Fungal spore suspension was prepared by brushing the plate surface with saline solution using a sterile swab and stored at $4{ }^{\circ} \mathrm{C}$ up to a maximum of 7 days. During this time, the fungal spores concentration was steady, as determined by plating serial dilution on PDA plates.

\subsection{Screening of Antifungal Activity}

The overlayed method was used for a fast initial screening of the antifungal activity of LAB strains against B. cinerea [28]. Briefly, $5 \mu \mathrm{L}$ of cultures at late exponential phase (approximately 16-h of incubation, according to previously generated standard growth curves) were spotted on MRS agar plates and incubated at $30^{\circ} \mathrm{C}$ for $24 \mathrm{~h}$. Then, plates were overlaid with $10 \mathrm{~mL}$ of Malt Extract (Oxoid) Soft Agar (0.75\% agar) inoculated (1:100 v/v) with a suspension containing approximately $1 \times 10^{6}$ spores $/ \mathrm{mL}$ of $B$. cinerea. After 3 days of incubation at $25^{\circ} \mathrm{C}, \mathrm{LAB}$ strains were discriminated on the basis of the halo of inhibition surrounding the spots and classified as strains of no $(-)$, mild (+), or strong $(++)$ inhibition, showing inhibition zone lower than $1 \mathrm{~mm}$, ranging from 1 to $5 \mathrm{~mm}$, or more than $5 \mathrm{~mm}$, respectively. Assays were performed in duplicate.

\subsection{Molecular Identification of LAB Species}

The LAB strains showing the best antifungal performance (inhibition halo higher than $10 \mathrm{~mm}$ ) were identified by sequencing of $16 \mathrm{~S}$ rRNA. Genomic DNA was extracted by using the UltraClean ${ }^{\circledR}$ Microbial DNA Isolation Kit, according to the manufacturer's instruction (Qiagen, Hilden, Germany), and the 16S rRNA gene amplified by using BSF8 (5'-AGAGTTTGATCCTGGCTCAG-3') and BSR1541 (5'-AAGGAGGTGATCCAGCCGCA$\left.3^{\prime}\right)$ primers. PCR was performed in $20 \mu \mathrm{L}$ reaction volume, containing $2 \mu \mathrm{L}$ buffer $10 \mathrm{X}$, $4 \mu \mathrm{L}$ buffer $\mathrm{Q}, 0.4 \mu \mathrm{L} \mathrm{dNTP}$ mix $(10 \mu \mathrm{M}), 0.5 \mu \mathrm{L}$ for each primer, $0.1 \mu \mathrm{L}$ Taq polymerase (Qiagen). The PCR protocol was as follows: denaturation at $94{ }^{\circ} \mathrm{C}$ for $4 \mathrm{~min}$, followed by 34 cycles of denaturation at $94{ }^{\circ} \mathrm{C}$ for $30 \mathrm{sec}$, annealing at $56{ }^{\circ} \mathrm{C}$ for $30 \mathrm{sec}$, elongation at $72{ }^{\circ} \mathrm{C}$ for $90 \mathrm{sec}$, and a final extension at $72{ }^{\circ} \mathrm{C}$ for $5 \mathrm{~min}$. Amplicons were analyzed by electrophoresis $(90 \mathrm{~V}, 30 \mathrm{~min}$ ) on $1 \%$ agarose gel containing ethidium bromide, visualized by UV fluorescence, and sequenced (Macrogen, Madrid, Spain). Results were submitted for comparison with sequences available at the NCBI database (GenBank) using the standard nucleotide-nucleotide homology search Basic Local Alignment Search Tool.

\subsection{Partial Characterization of the Antifungal Activity of LAB Cell-Free Supernatant}

The $\mathrm{LAB}$ strains showing strong antifungal ability were grown until the late exponential and stationary phase by incubation in MRS at $30^{\circ} \mathrm{C}$ for 24 and $48 \mathrm{~h}$, respectively. Growth curves were determined by monitoring the optical density at $600 \mathrm{~nm}\left(\mathrm{OD}_{600}\right)$ for $48 \mathrm{~h}$ using the plate reader BioTek Eon spectrophotometer (BioTek, Winooski, VT, USA). The corresponding cell-free supernatants (identified as CFS24 and CFS48) were obtained by centrifugation $(8000 \times g \times 5 \mathrm{~min})$ and filtration $(0.45 \mu \mathrm{m}$-pore-size filter; VWR international, West Chester, PA, USA). In order to partially characterize the metabolites responsible for the antagonistic activity, an aliquot of the CFSs was neutralized $(\mathrm{pH}=7)$ by adding $\mathrm{KOH}$ $1 \mathrm{M}$ (Sigma-Aldrich, St. Louis, MO, USA). The antifungal activity of CFSs was determined by using the method of radial growth inhibition of hyphae [29]. Briefly, PDA plates were supplemented with $20 \%(v / v)$ of CFSs, and $10 \mu \mathrm{L}$ of a freshly-prepared solution containing 
approximately $1 \times 10^{6}$ spores $/ \mathrm{mL}$ of $B$. cinerea were spotted at the center of the plate. The control plates were prepared by adding the same concentration of sterile MRS broth. Inhibition percentage was determined by measuring the radial growth of the hyphae after 24,48 , and $72 \mathrm{~h}$ of incubation at $24^{\circ} \mathrm{C}$. All the assays were performed in triplicate.

\subsection{Quantification of Lactic Acid}

LAB strains were inoculated from cryopreserved stock (1:1000 $v / v)$ in MRS, and aliquots of cultures were collected at $6,24,30$, and $48 \mathrm{~h}$ of growth, centrifuged and filtered as above. Then, the $\mathrm{pH}$ was measured (Mettler Toledo, Columbus, OH, USA), and the amount of both L-lactic acid and D-lactic acid determined spectrophotometrically in a plate reader (BioTek) by using a specific enzymatic kit (Biogamma, Rome, Italy) according to manufacturer's instructions. Three different biological and five technical replicates were carried out.

\subsection{Fruit Decay Assay}

Healthy "Hayward" kiwifruits (Actinidia chinensis var. deliciosa A. Chevalier) were purchased in a local market, washed twice with sterile distilled water and dried. After drying, fruits were cut and divided into similar pieces by using a sterile lancet. For the assay, kiwifruit pieces were artificially contaminated or not with $B$. cinerea at a concentration of about $1 \times 10^{6}$ spores $/ \mathrm{mL}$ (freshly-prepared) by dipping for $30 \mathrm{~s}$ in MRS (control), MRS containing Fenhexamid $4 \mathrm{mg} / \mathrm{L}$ (Teldor Plus, Bayer, Leverkusen, Germany), or in the CFS48 from PAN01 and UFG 121. Then, fruits were air-dried under a laminar flow hood. After drying, three pieces of kiwifruits for each treatment were stored in Petri dishes at $25^{\circ} \mathrm{C}$ for 3 days or at $4{ }^{\circ} \mathrm{C}$ for 14 days. Each treatment was performed in triplicate. The decay development was monitored daily through image acquisition by using a vision computer system equipped with a digital color camera (EOS 00D, Canon, Melville, NY, USA) located vertically on a matte black background at a distance of $0.45 \mathrm{~m}$ [28].

\subsection{Sensorial Quality Analysis}

A group of ten trained panelists performed the sensory evaluations of kiwifruits at the end of the storage. Before evaluations, panelists were trained in order to recognize and score the quality attributes. Color, mold occurrence, overall acceptance, visual quality, and freshness were evaluated using a hedonic scale from 1 to 5 , where $1=$ not edible $/ 100 \%$ mold presence, to $5=$ very fresh $/ 0 \%$ mold presence, with 3 fixed as limit of marketability.

\subsection{Statistical Analysis}

The distribution of data was analyzed by using the Kolmogorov-Smirnov test of normality. One-way ANOVA using StatGraphics Centurion XVI.I (StatPoint Technologies Inc., Warrenton, VA, USA), applying Tukey's test was used to determine any statistically significant difference $(p \leq 0.05)$.

\section{Results and Discussion}

\subsection{Screening of the Antifungal Activity of Lactic Acid Bacteria}

LAB from sourdoughs have been widely investigated for their antifungal activity [30-32], and successfully proposed for increasing the shelf-life of bakery products [18,33-36]. In this work, we investigated the effectiveness of $300 \mathrm{LAB}$ strains isolated from traditional sourdoughs to contrast $B$. cinerea, a specific and diffused spoilage microbe of fruits and vegetables.

The LAB strains mainly showed only a poor or modest ability to inhibit the fungal target, using the overlayed method. In fact, based on the inhibition halo, it was found that $98 \%$ of the tested LAB strains were barely able to inhibit B. cinerea CECT 20973 (inhibition halo lower than $3 \mathrm{~mm}$ ), while only six strains (2\%) exerted a strong antagonism, showing an inhibition halo higher than $10 \mathrm{~mm}$. This result agrees with the analysis of the antifungal activity performed by Cheong et al. [37], which screened about 900 LAB strains, observing that only 12 isolates (less than $2 \%$ ) had a strong antagonistic activity against common 
cheese spoilage molds belonging to the genera Aspergillus, Penicillium, and Cladosporium, suggesting that the ability to deeply counteract the development of specific fungal targets can be a trait not widely diffused among LAB (probably species- and strain-dependent), regardless from the food matrices.

The strains with the best antifungal performances were selected for further in vitro characterization and identified by sequencing the 16S rRNA (Table 1). The molecular analysis revealed that all the strains belonged to Lactiplantibacillus plantarum species (formerly Lactobacillus plantarum) [38]. This evidence confirmed the general antimicrobial potential of L. plantarum species [39-41] and the rising evidence of a possible contribution of lactobacilli, particularly L. plantarum, in the microbial-based bio-control activity against B. cinerea on fruits [27,42-44].

Table 1. The six lactic acid bacteria (LAB) strains with best antifungal activity against B. cinerea.

\begin{tabular}{cccc}
\hline LAB Strains & Source & Species & Reference \\
\hline M04 & Sourdough-C & L. plantarum & {$[18]$} \\
PAN01 & Sourdough-B & L. plantarum & {$[18]$} \\
M12 & Sourdough-C & L. plantarum & {$[18]$} \\
C01Rib & Sourdough-E & L. plantarum & {$[18]$} \\
UFG 121 & Sourdough-A & L. plantarum & {$[28]$} \\
RIS10 & Sourdough-D & L. plantarum & {$[18]$} \\
\hline
\end{tabular}

\subsection{Anti-Botrytis Activity of Cell-Free Supernatants}

In order to determine if the antifungal activity was due to direct antagonism or to the production of some metabolites, the CFSs were collected after 24 (CFS24) and 48 (CFS48) hours of incubation, a time corresponding to the late exponential and late stationary phase, respectively (an example is shown in Figure 1). The $\mathrm{pH}$ of each CFS was measured, as reported in Table 2.

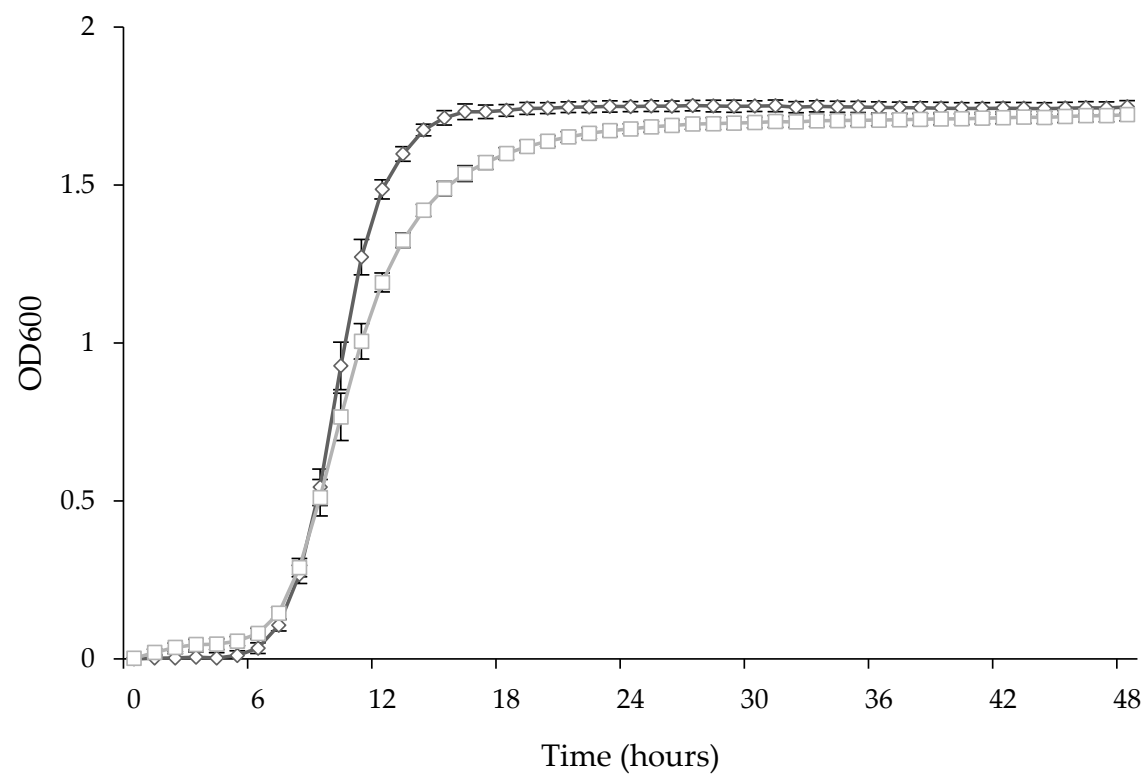

Figure 1. Growth curves of L. plantarum UFG 121 (square) and L. plantarum PAN01 (diamond). Data shown are mean \pm SD (standard deviation) of three independent experiments. 
Table 2. $\mathrm{pH}$ of the CFSs obtained after 24 (CFS24) and 48 (CFS48) h of growth in MRS at $37^{\circ} \mathrm{C}$.

\begin{tabular}{ccc}
\hline \multirow{2}{*}{ LAB Strains } & & pH \\
\cline { 2 - 3 } & CFS24 & CFS48 \\
\hline M04 & 3.95 & 3.72 \\
PAN01 & 3.57 & 3.54 \\
M12 & 3.76 & 3.63 \\
C01Rib & 3.65 & 3.56 \\
UFG 121 & 3.80 & 3.60 \\
RIS10 & 3.57 & 3.54 \\
\hline
\end{tabular}

The inhibition was monitored based on the hyphae's radial growth in plates containing or not $20 \%$ of the different CFSs, as described by Wang et al. [29]. As shown in Figure 2, the inhibition detected after $24 \mathrm{~h}$ of incubation dropped by half after $48 \mathrm{~h}$, while it was not detectable after $72 \mathrm{~h}$, indicating that the tested strains were able to delay at different extents, but not to inhibit completely, the growth of B. cinerea CECT 20973.

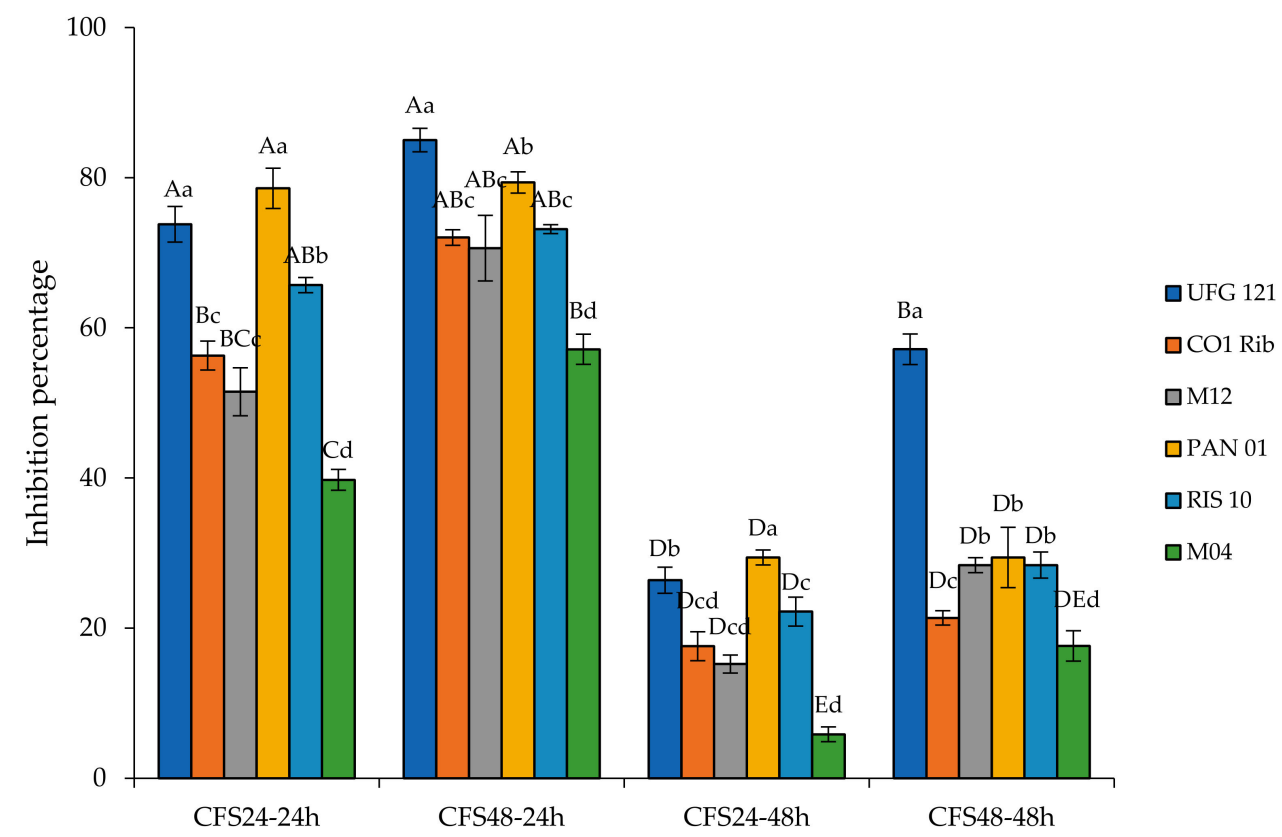

Figure 2. Hyphal radial growth inhibition of B. cinerea after $24 \mathrm{~h}$ and $48 \mathrm{~h}$ of incubation at $25^{\circ} \mathrm{C}$ on plates of malt extract agar supplemented with $20 \%$ of CFS24 and CFS48 of the selected LAB strains. Capital letters indicate significant differences among the inhibition percentage of CFSs at all the experimental conditions. Lowercase letters indicate significant differences among the inhibition percentage of CFSs inside each experimental condition.

In detail, CFSs24 inhibited B. cinerea CECT 20973, between a minimum of 40\% (M04) up to a maximum of about $80 \%$ (PAN01), after $24 \mathrm{~h}$ of mold growth. At this time of incubation, the antifungal activity of the CFSs 48 of each L. plantarum strain notably increased, probably due to a further reduction of the corresponding $\mathrm{pH}$. However, after two days of incubation, the ability to contrast the B. cinerea CECT 20973 growth was strongly reduced, ranging between 5 and 30\% of inhibition for CFSs24 of M04 and PAN01, respectively. Interestingly, only CFS48 of L. plantarum UFG 121 showed a high inhibition capability after two days of the fungal growth (about $60 \%$ ), which was almost double than what was observed for the CFSs 48 of the other strains. These findings extended the knowledge concerning antimicrobial applications of CFSs from L. plantarum strains. In fact, several studies reported the potential of $L$. plantarum cell-free supernatants against foodborne pathogens (e.g., Escherichia coli, Pseudomonas aeruginosa, and Staphylococcus aureus [45-47]), other human pathogens (e.g., oral Candida species [48]), microbes producers of toxic compounds in foods (e.g., fumonisin producing Fusarium proliferatum, amine-positive bacteria $[49,50])$, 
spoilage fungi (e.g., Aspergillus niger, Aspergillus flavus, and Fusarium oxysporum [51,52]), and plant pathogens (e.g., Pseudomonas syringae pv. actinidiae, Xanthomonas arboricola pv. pruni, and Xanthomonas fragariae [53]). Additionally, few studies delved into the application of L. plantarum to limit the impact of $B$. cinerea as a fungal plant pathogen $[29,54]$. On the opposite, for the first time, the present study investigated the limitation of $B$. cinerea for post-harvest application on fruits/vegetables.

In general, our results showed some relationship between lower $\mathrm{pH}$ and higher antifungal activity, suggesting that an early production of organic acids might be responsible for the detected antagonism. Accordingly, in line with the evidence reported by Daranas et al. [53], when the assay was performed by using the corresponding neutralized CFSs, no inhibition was detected, corroborating the hypothesis that the antifungal activity is due to the production of organic acids. These compounds are the main products of the LAB's secondary metabolism, and they are well-known for their preservative effectiveness $[55,56]$. However, it is noteworthy to point out that the $\mathrm{pH}$ of all CFSs48 were almost similar, except for M04 strain (that always showed the lowest inhibition), suggesting that a different composition of organic acids and/or the production of other compounds could be involved in the antifungal activity [57].

Thus, lactic acid production was monitored during $48 \mathrm{~h}$ in L. plantarum UFG 121 and L. plantarum PAN01, selected as the best antagonist strains (Table 3). Since L. plantarum can produce both L-lactate and D-lactate, each enantiomer was detected. After $24 \mathrm{~h}$ of growth, L-lactic acid production was slightly higher for strain UFG 121 than PAN01 (about 17 and $14 \mathrm{~g} / \mathrm{L}$, respectively). This difference further rose until achieving a final amount of about 27 and $20 \mathrm{~g} / \mathrm{L}$ in $48 \mathrm{~h}$-old cultures. Interestingly, L-lactate was the dominant form, corresponding to a concentration higher than $85 \%$ of the total. Moreover, the fraction of D-lactate produced by strain 121 was about double that of strain PAN01.

Table 3. $\mathrm{pH}$ and lactic acid (L- and D-enantiomers) production by UFG 121 and PAN01 strains monitored during $48 \mathrm{~h}$ of growth in MRS media.

\begin{tabular}{|c|c|c|c|c|c|c|c|c|}
\hline \multicolumn{6}{|c|}{ UFG 121} & \multicolumn{3}{|c|}{ PAN01 } \\
\hline Time (h) & $\mathrm{pH}$ & Lactic Acid (g/L) & L-Lactate $(\mathrm{g} / \mathrm{L})$ & D-Lactate $(g / L)$ & $\mathrm{pH}$ & Lactic Acid (g/L) & L-Lactate $(g / L)$ & D-Lactate $(\mathrm{g} / \mathrm{L})$ \\
\hline 6 & 6.53 & $0.48 \pm 0.07^{\mathrm{dD}}$ & $0.38 \pm 0.02 \mathrm{dD}$ & $0.10 \pm 0.07^{\mathrm{cE}}$ & 6.54 & $0.49 \pm 0.22 \mathrm{dD}$ & $0.31 \pm 0.25^{\mathrm{cD}}$ & $0.09 \pm 0.02 \mathrm{dE}$ \\
\hline 24 & 3.80 & $16.93 \pm 0.55^{\mathrm{cBC}}$ & $14.76 \pm 0.50^{\mathrm{cC}}$ & $2.17 \pm 0.65^{\mathrm{bBC}}$ & 3.57 & $14.70 \pm 0.03^{c C}$ & $14.14 \pm 0.02^{\mathrm{bC}}$ & $0.56 \pm 0.07^{\mathrm{cD}}$ \\
\hline 30 & 3.68 & $20.45 \pm 0.74$ bВ & $17.92 \pm 0.74 \mathrm{bB}$ & $2.53 \pm 0.76^{\mathrm{bB}}$ & 3.55 & $16.17 \pm 0.19 \mathrm{bcBC}$ & $14.89 \pm 0.11^{b C}$ & $1.28 \pm 0.46^{\mathrm{bC}}$ \\
\hline 48 & 3.60 & $27.18 \pm 0.30^{\mathrm{aA}}$ & $22.27 \pm 0.32^{\mathrm{aA}}$ & $4.91 \pm 0.24^{\mathrm{aA}}$ & 3.54 & $20.59 \pm 0.24^{\mathrm{aB}}$ & $17.94 \pm 0.06^{\mathrm{aB}}$ & $2.64 \pm 0.72^{\mathrm{aB}}$ \\
\hline
\end{tabular}

Values are the average of three biological replicates. Capital letters indicate significant differences among the production of the same acid by the two strains. Lowercase letters indicate significant differences among the production of the same acid by the same strain.

Similarly, the antagonistic strain Lactiplantibacillus pentosus LOCK 0979, a species very close to L. plantarum, produced 93\% of L-lactic acid in MRS. However, in presence of sorbitol and galactosyl-polyols, the amount of D-lactate increased up to a concentration higher than $30 \%$ [58]. Interestingly, recent works report a rise of the antifungal activity in association with different polyols that was related to significant modification of the acid metabolite profile of the bacterial culture supernatant [59,60]. Although our results are in apparent contrast to what reported in Table 2, since the higher production of lactic acid observed for L. plantarum UFG 121 corresponded to a high $\mathrm{pH}$ of this strain than PAN01, the occurrence of other organic acids, probably less effective against $B$. cinerea, could determine the lower $\mathrm{pH}$ value observed for PAN01. On the other hand, it is well known that antagonistic compounds might contribute to the overall inhibition by having a synergistic or additive effect [61]. For example, as previously determined by Russo et al. [28], UFG 121 strain produced low amounts of phenyllactic acid, a compound displaying a broad spectrum of antifungal activity [20], which might partially explain this apparent incongruence. Indeed, it is presumed that the behavior of the antifungal activity is positively related to the phenyllactic acid and 4-hydroxyphenyllactic acid content in LAB culture filtrates [62]. However, a wide variety of other volatile organic acids (mainly including acetic, propanoic, butanoic, octanoic, and hydroxyl acids) have been suggested as active against $B$. cinerea, 
and the microorganisms responsible for their production proposed as biocontrol agents on strawberry, vine, and grape berries [63-65].

\subsection{Anti-Botrytis Activity on Cut Kiwifruits}

In order to investigate the potential of L. plantarum strains as protective treatment to delay the decay during storage of fruit commodities, CFS48 of L. plantarum PAN01 and UFG 121 strains were tested for a preliminary in vivo assay by using freshly cut kiwifruit as a food model. CFS were applied by dipping, a process usually employed to transfer antimicrobial, antibrowning, or texture preservative compounds to fresh-cut products. A fungicide (e.g., Fenhexamid) classified as a minimal risk to human health and environment for the control of grey mold in pre- and post-harvest was used to compare the efficacy of the proposed approach. Kiwifruits were stored for 3 days at $25^{\circ} \mathrm{C}$, to mimic a thermal abuse that could encourage the development of the spoiler, and at $4{ }^{\circ} \mathrm{C}$ for 14 days, simulating a correct management of the cold chain.

As expected, when the assay was carried out at room temperature (Figure 3A) a fast development of $B$. cinerea was detected on all the artificially contaminated samples, although the fungal growth seems to be delayed in kiwifruits treated with CFS48 from UFG 121 strain and the chemical.

A

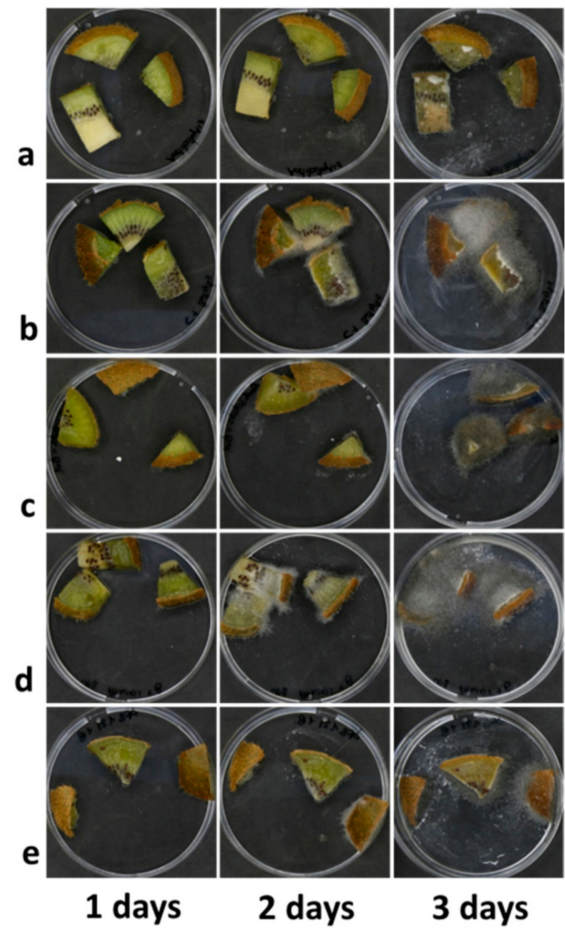

B

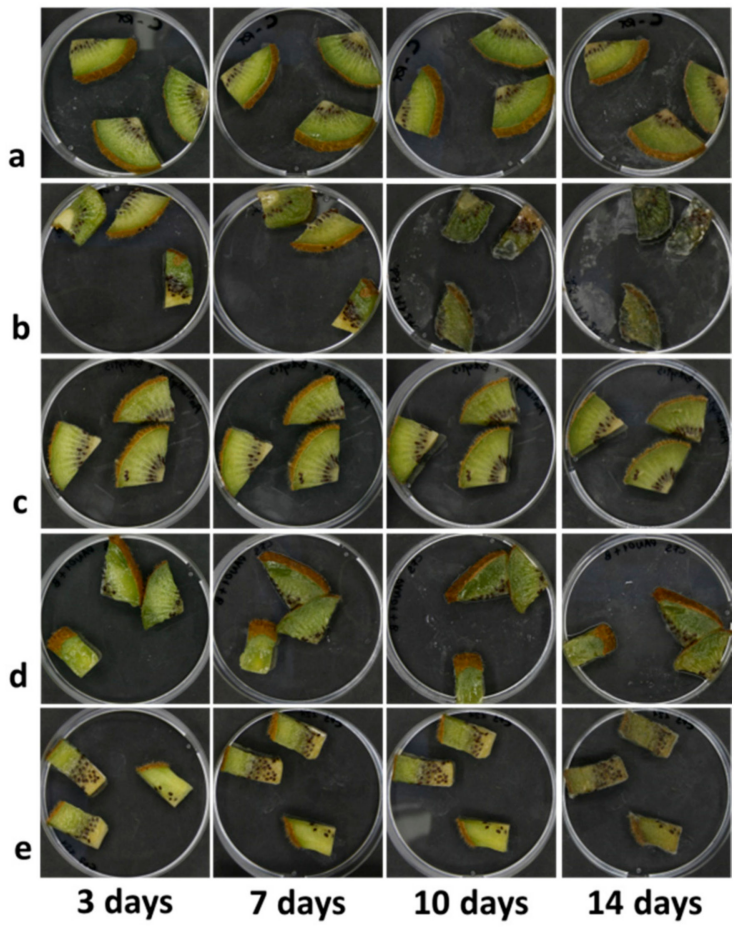

Figure 3. Image acquisition of kiwifruit pieces non- (a) or artificially contaminated with B. cinerea CECT 20973 (b) and treated with Fenhexamid (c), CFS48 of L. plantarum PAN01 (d), or UFG 121 (e), and stored for 3 days at $25^{\circ} \mathrm{C}(\mathbf{A})$ or for two weeks at $4{ }^{\circ} \mathrm{C}($ B) .

Under cold storage conditions (Figure 3B), B. cinerea began to develop only after the seventh day in non-treated contaminated samples, covering the whole fruit's surface on the tenth day. In contrast, molds occurrence was only minimally detectable after two weeks in kiwifruits submitted to CFS48 treatments. No fungal growth was disclosed in control and chemically-treated samples.

In particular, kiwifruits stored at $4{ }^{\circ} \mathrm{C}$ were subjected to several modifications, such as color changes, loss of firmness, dehydration of the cut surfaces, probably associated with alterations in nutritional and organoleptic quality, started to occur after 10 days of preservation, regardless of contamination with B. cinerea (Figures $3 B$ and 4 ). These changes 
could be induced by biochemical reactions associated with cell senescence, accelerated by unit operations, such as cutting and washing.

Figure 4 show changes in sensory parameters after 10 days and at the end of storage time in cold-stored kiwifruits. As expected, it was observed that artificial contamination of kiwifruit pieces with $B$. cinerea greatly affected the product's quality. Control and treated with Fenhexamid samples showed the best performance during storage, being still marketable after two weeks. At the same time, kiwifruits treated with CFS48 from L. plantarum UFG 121 showed better behaviors than PAN01 reaching not acceptable overall quality anyhow. Interestingly, after 10 days of cold storage, the kiwifruit pieces dipped in CFS48 of UFG 121 were considered to be of sufficient quality for marketing, as no significant differences were found with the control fruits.

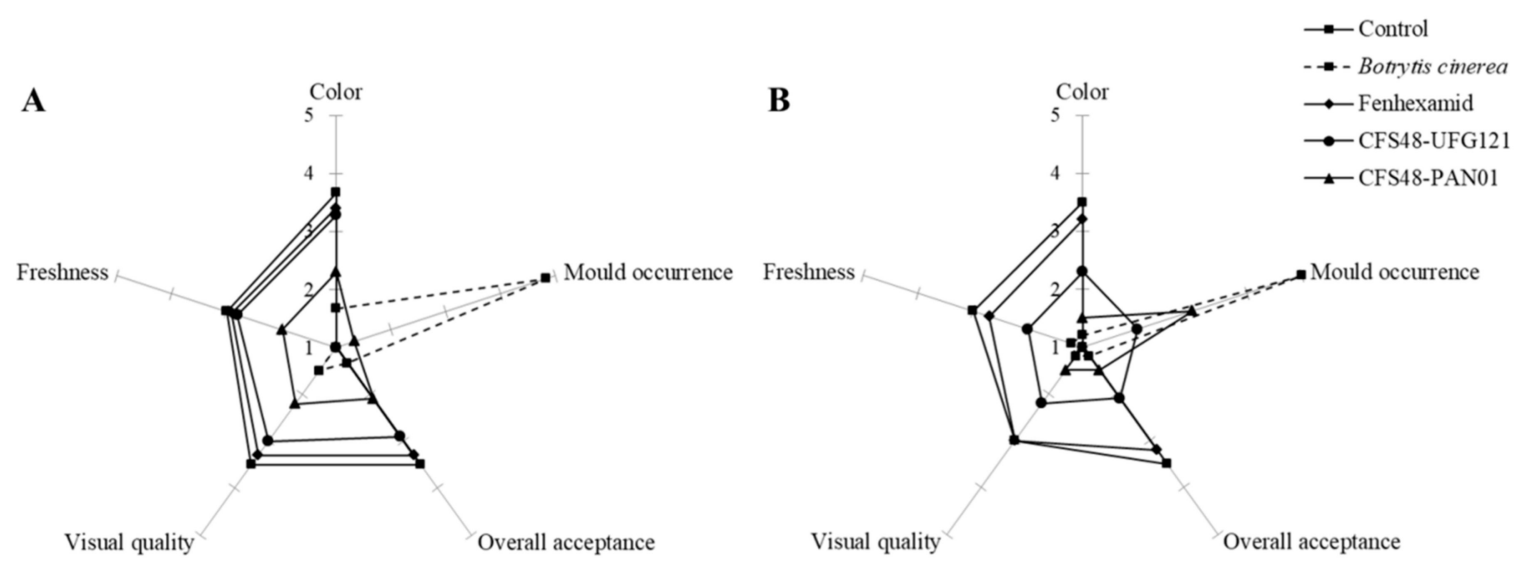

Figure 4. Sensorial evaluation of freshly cut kiwifruits after $10(\mathbf{A})$ and 14 days (B) of storage at $4{ }^{\circ} \mathrm{C}$.

This time is consistent with what observed for fresh-cut pear submitted to a postharvest calcium supplementation with Lactobacillus rhamnosus GG [66], while coated kiwi slices loaded with probiotic $L$. plantarum retained overall acceptability and physicochemical characteristics for five days of cold storage [29].

Therefore, our results suggest that, despite the LAB strains analyzed might not be used for applications in which a complete inhibition of $B$. cinerea is required, they could still be valuable in the design of protective microbial-based solutions to delay its growth, extending shelf life and improving fruit marketability. In particular, it was further confirmed the broad antifungal activity of strain UFG 121 in different food matrices [17,28], indicating potential applications also in the biocontrol of fruit products. Moreover, in this study, conditions encouraging fungal contamination, including a high level of spores and packaging in passive atmosphere, have been evaluated, suggesting a potential greater biocontrol effectiveness than what was observed. Accordingly, it has been reported that that the antimicrobial effectiveness of live bacteria on fresh-cut fruits was positively correlated with antagonist concentration $[67,68]$. However, the addition of viable bacteria could drive detrimental fermentations, leading to off-flavors' production impacting the overall quality of the fruits [68].

\section{Conclusions}

Filamentous fungi are responsible for significant food deterioration, as well as safety concerns due to their potential ability to produce mycotoxins. In recent years, LAB have been extensively studied for their ability to counteract the fungal growth, and they can be considered as a promising strategy for the bio-conservation of fruits and vegetables [69]. In particular, increasing shelf life without the addition of chemical additives is one of the main challenges for the sector. In this work, we selected two Lactiplantibacillus plantarum strains from a large cohort of LAB based on their ability to contrast the growth of $B$. cinerea likely due to the production of organic acids. The CFS of both strains was employed on 
artificially contaminated cut kiwifruits showing a promising capability to delay the fungal growth. Therefore, further studies should be encouraged to investigate innovative technologies to deliver antifungal metabolites from microbial origin, as well their combination with physical treatments, in order to enhance safety and shelf life without altering the overall quality of the product.

Author Contributions: N.D.S.: Investigation, Data curation, Visualization, Methodology, and Writing-original draft. V.C.: Conceptualization, Supervision, and Writing-review and editing. M.L.V.d.C.: Investigation, Data curation, Methodology, and Writing—original draft. M.L.A.: Supervision, and Writing-review and editing. S.B.: Investigation, and Data curation. G.C.: Conceptualization, Supervision, and Writing-review and editing. D.D.: Conceptualization, and Writing-review and editing. G.S.: Conceptualization, Resources, Supervision, and Writing-review and editing. P.R.: Conceptualization, Supervision, Investigation, Data curation, Writing—original draft, and Writingreview and editing. All authors have read and agreed to the published version of the manuscript.

Funding: This research received no external funding.

Institutional Review Board Statement: Not applicable.

Informed Consent Statement: Not applicable.

Data Availability Statement: Please refer to suggested Data Availability Statements in section "MDPI Research Data Policies" at https://www.mdpi.com/ethics.

Acknowledgments: Pasquale Russo is the beneficiary of a grant by MIUR in the framework of 'AIM: Attraction and International Mobility' (PON R\&I2014-2020) (practice code D74I18000190001).

Conflicts of Interest: The authors declare no conflict of interest.

\section{References}

1. Zhang, H.; Zhao, Q.; Lan, T.; Geng, T.; Gao, C.; Yuan, Q.; Zhang, Q.; Xu, P.; Sun, X.; Liu, X.; et al. Comparative Analysis of Physicochemical Characteristics, Nutritional and Functional Components and Antioxidant Capacity of Fifteen Kiwifruit (Actinidia) Cultivars-Comparative Analysis of Fifteen Kiwifruit (Actinidia) Cultivars. Foods 2020, 9, 1267. [CrossRef]

2. Stonehouse, W.; Gammon, C.S.; Beck, K.L.; Conlon, C.A.; von Hurst, P.R.; Kruger, R. Kiwifruit: Our Daily Prescription for Health. Can. J. Physiol. Pharmacol. 2012, 91, 442-447. [CrossRef]

3. Hunter, D.C.; Skinner, M.A.; Ferguson, A.R. Chapter 12-Kiwifruit and health. In Fruits, Vegetables, and Herbs; Watson, R.R., Preedy, V.R., Eds.; Academic Press: Cambridge, MA, USA, 2016; pp. 239-269. ISBN 978-0-12-802972-5.

4. Richardson, D.P.; Ansell, J.; Drummond, L.N. The Nutritional and Health Attributes of Kiwifruit: A Review. Eur. J. Nutr. 2018, 57, 2659-2676. [CrossRef]

5. FAO. FAOSTAT Statistical Database. Available online: http://www.fao.org/faostat/en/\#compare (accessed on 3 March 2021).

6. Rushing, J.R. Kiwifruit. In The Commercial Storage of Fruits, Vegetables, and Florist and Nursery Stocks; Gross, K.C., Wang, C.Y., Saltveit, M., Eds.; USDA Agricultural Research Service: Beltsville, MD, USA, 2016; pp. 371-376.

7. Cornacchia, R.; Amodio, M.L.; Rinaldi, R.; Colelli, G. Effect of 1-Methylcyclopropene and Controlled Atmosphere on Storage of Kiwifruits. Fresh Prod. 2008, 2, 22-25.

8. Oliveira, P.M.; Zannini, E.; Arendt, E.K. Cereal Fungal Infection, Mycotoxins, and Lactic Acid Bacteria Mediated Bioprotection: From Crop Farming to Cereal Products. Food Microbiol. 2014, 37, 78-95. [CrossRef]

9. Dean, R.; Kan, J.a.L.V.; Pretorius, Z.A.; Hammond-Kosack, K.E.; Pietro, A.D.; Spanu, P.D.; Rudd, J.J.; Dickman, M.; Kahmann, R.; Ellis, J.; et al. The Top 10 Fungal Pathogens in Molecular Plant Pathology. Mol. Plant Pathol. 2012, 13, 414-430. [CrossRef] [PubMed]

10. Minas, I.S.; Karaoglanidis, G.S.; Manganaris, G.A.; Vasilakakis, M. Effect of Ozone Application during Cold Storage of Kiwifruit on the Development of Stem-End Rot Caused by Botrytis cinerea. Postharvest Biol. Technol. 2010, 58, 203-210. [CrossRef]

11. Mari, M.; Spadoni, A.; Ceredi, G. Alternative Technologies to Control Postharvest Diseases of Kiwifruit. Stewart Postharvest Rev. 2015, 11, 1-5.

12. De Simone, N.; Pace, B.; Grieco, F.; Chimienti, M.; Tyibilika, V.; Santoro, V.; Capozzi, V.; Colelli, G.; Spano, G.; Russo, P. Botrytis cinerea and Table Grapes: A Review of the Main Physical, Chemical, and Bio-Based Control Treatments in Post-Harvest. Foods 2020, 9, 1138. [CrossRef] [PubMed]

13. Fillinger, S.; Leroux, P.; Auclair, C.; Barreau, C.; Hajj, C.A.; Debieu, D. Genetic Analysis of Fenhexamid-Resistant Field Isolates of the Phytopathogenic Fungus Botrytis cinerea. Antimicrob. Agents Chemother. 2008, 52, 3933-3940. [CrossRef]

14. Romanazzi, G.; Smilanick, J.L.; Feliziani, E.; Droby, S. Integrated Management of Postharvest Gray Mold on Fruit Crops. Postharvest Biol. Technol. 2016, 113, 69-76. [CrossRef] 
15. De Simone, N.; Capozzi, V.; Amodio, M.L.; Colelli, G.; Spano, G.; Russo, P. Microbial-Based Biocontrol Solutions for Fruits and Vegetables: Recent Insight, Patents, and Innovative Trends. Recent Pat. Food Nutr. Agric. 2021, 12, 1. [CrossRef]

16. Russo, P.; Spano, G.; Capozzi, V. Safety evaluation of starter cultures. In Starter Cultures in Food Production; John Wiley \& Sons, Ltd.: Hoboken, NJ, USA, 2017; pp. 101-128. ISBN 978-1-118-93379-4.

17. Russo, P.; Fares, C.; Longo, A.; Spano, G.; Capozzi, V. Lactobacillus plantarum with Broad Antifungal Activity as a Protective Starter Culture for Bread Production. Foods 2017, 6, 110. [CrossRef]

18. Arena, M.P.; Russo, P.; Spano, G.; Capozzi, V. Exploration of the Microbial Biodiversity Associated with North Apulian Sourdoughs and the Effect of the Increasing Number of Inoculated Lactic Acid Bacteria Strains on the Biocontrol against Fungal Spoilage. Fermentation 2019, 5, 97. [CrossRef]

19. Agriopoulou, S.; Stamatelopoulou, E.; Sachadyn-Król, M.; Varzakas, T. Lactic Acid Bacteria as Antibacterial Agents to Extend the Shelf Life of Fresh and Minimally Processed Fruits and Vegetables: Quality and Safety Aspects. Microorganisms 2020, 8, 952. [CrossRef]

20. Cortés-Zavaleta, O.; López-Malo, A.; Hernández-Mendoza, A.; García, H.S. Antifungal Activity of Lactobacilli and Its Relationship with 3-Phenyllactic Acid Production. Int. J. Food Microbiol. 2014, 173, 30-35. [CrossRef]

21. Brosnan, B.; Coffey, A.; Arendt, E.K.; Furey, A. Rapid Identification, by Use of the LTQ Orbitrap Hybrid FT Mass Spectrometer, of Antifungal Compounds Produced by Lactic Acid Bacteria. Anal. Bioanal. Chem. 2012, 403, 2983-2995. [CrossRef] [PubMed]

22. Iglesias, M.B.; Abadias, M.; Anguera, M.; Sabata, J.; Viñas, I. Antagonistic Effect of Probiotic Bacteria against Foodborne Pathogens on Fresh-Cut Pear. LWT Food Sci. Technol. 2017, 81, 243-249. [CrossRef]

23. Iglesias, M.B.; López, M.L.; Echeverría, G.; Viñas, I.; Zudaire, L.; Abadias, M. Evaluation of Biocontrol Capacity of Pseudomonas graminis CPA-7 against Foodborne Pathogens on Fresh-Cut Pear and Its Effect on Fruit Volatile Compounds. Food Microbiol. 2018, 76, 226-236. [CrossRef]

24. Leneveu-Jenvrin, C.; Charles, F.; Barba, F.J.; Remize, F. Role of Biological Control Agents and Physical Treatments in Maintaining the Quality of Fresh and Minimally-Processed Fruit and Vegetables. Crit. Rev. Food Sci. Nutr. 2020, 60, $2837-2855$. [CrossRef] [PubMed]

25. Klewicka, E.; Sójka, M.; Klewicki, R.; Kołodziejczyk, K.; Lipińska, L.; Nowak, A. Ellagitannins from Raspberry (Rubus Idaeus L.) Fruit as Natural Inhibitors of Geotrichum Candidum. Molecules 2016, 21, 908. [CrossRef] [PubMed]

26. Klewicka, E.; Sójka, M.; Ścieszka, S.; Klewicki, R.; Milczarek, A.; Lipińska, L.; Kołodziejczyk, K. The Antimycotic Effect of Ellagitannins from Raspberry (Rubus Idaeus L.) on Alternaria Alternata ŁOCK 0409. Eur. Food Res. Technol. 2020, 246, 1341-1349. [CrossRef]

27. Hashemi, S.M.B.; Jafarpour, D. Bioactive Edible Film Based on Konjac Glucomannan and Probiotic Lactobacillus plantarum Strains: Physicochemical Properties and Shelf Life of Fresh-Cut Kiwis. J. Food Sci. 2021, 86, 513-522. [CrossRef] [PubMed]

28. Russo, P.; Arena, M.P.; Fiocco, D.; Capozzi, V.; Drider, D.; Spano, G. Lactobacillus plantarum with Broad Antifungal Activity: A Promising Approach to Increase Safety and Shelf-Life of Cereal-Based Products. Int. J. Food Microbiol. 2017, 247, 48-54. [CrossRef] [PubMed]

29. Wang, H.; Yan, Y.; Wang, J.; Zhang, H.; Qi, W. Production and Characterization of Antifungal Compounds Produced by Lactobacillus plantarum IMAU10014. PLoS ONE 2012, 7, e29452. [CrossRef]

30. Axel, C.; Brosnan, B.; Zannini, E.; Furey, A.; Coffey, A.; Arendt, E.K. Antifungal Sourdough Lactic Acid Bacteria as Biopreservation Tool in Quinoa and Rice Bread. Int. J. Food Microbiol. 2016, 239, 86-94. [CrossRef]

31. Hassan, Y.I.; Zhou, T.; Bullerman, L.B. Sourdough Lactic Acid Bacteria as Antifungal and Mycotoxin-Controlling Agents. Food Sci. Technol. Int. 2016, 22, 79-90. [CrossRef]

32. Bartkiene, E.; Lele, V.; Ruzauskas, M.; Domig, K.J.; Starkute, V.; Zavistanaviciute, P.; Bartkevics, V.; Pugajeva, I.; Klupsaite, D.; Juodeikiene, G. Lactic Acid Bacteria Isolation from Spontaneous Sourdough and Their Characterization Including Antimicrobial and Antifungal Properties Evaluation. Microorganisms 2020, 8, 64. [CrossRef]

33. Dal Bello, F.; Clarke, C.I.; Ryan, L.A.M.; Ulmer, H.; Schober, T.J.; Ström, K.; Sjögren, J.; Van Sinderen, D.; Schnürer, J.; Arendt, E.K. Improvement of the Quality and Shelf Life of Wheat Bread by Fermentation with the Antifungal Strain Lactobacillus plantarum FST 1.7. J. Cereal Sci. 2007, 45, 309-318. [CrossRef]

34. Huh, C.K.; Hwang, T.Y. Identification of Antifungal Substances of Lactobacillus sakei subsp. ALI033 and Antifungal Activity against Penicillium brevicompactum Strain FI02. Prev. Nutr. Food Sci. 2016, 21, 52. [CrossRef]

35. Axel, C.; Brosnan, B.; Zannini, E.; Peyer, L.C.; Furey, A.; Coffey, A.; Arendt, E.K. Antifungal Activities of Three Different Lactobacillus Species and Their Production of Antifungal Carboxylic Acids in Wheat Sourdough. Appl. Microbiol. Biotechnol. 2016, 100, 1701-1711. [CrossRef]

36. Quattrini, M.; Liang, N.; Fortina, M.G.; Xiang, S.; Curtis, J.M.; Gänzle, M. Exploiting Synergies of Sourdough and Antifungal Organic Acids to Delay Fungal Spoilage of Bread. Int. J. Food Microbiol. 2019, 302, 8-14. [CrossRef]

37. Cheong, E.Y.; Sandhu, A.; Jayabalan, J.; Le, T.T.K.; Nhiep, N.T.; Ho, H.T.M.; Zwielehner, J.; Bansal, N.; Turner, M.S. Isolation of Lactic Acid Bacteria with Antifungal Activity against the Common Cheese Spoilage Mold Penicillium commune and Their Potential as Biopreservatives in Cheese. Food Control 2014, 46, 91-97. [CrossRef]

38. Zheng, J.; Wittouck, S.; Salvetti, E.; Franz, C.M.; Harris, H.M.; Mattarelli, P.; O’Toole, P.W.; Pot, B.; Vandamme, P.; Walter, J. A Taxonomic Note on the Genus Lactobacillus: Description of 23 Novel Genera, Emended Description of the Genus Lactobacillus 
Beijerinck 1901, and Union of Lactobacillaceae and Leuconostocaceae. Int. J. Syst. Evol. Microbiol. 2020, 70, 2782-2858. [CrossRef] [PubMed]

39. Hu, C.-H.; Ren, L.-Q.; Zhou, Y.; Ye, B.-C. Characterization of Antimicrobial Activity of Three Lactobacillus plantarum Strains Isolated from Chinese Traditional Dairy Food. Food Sci. Nutr. 2019, 7, 1997-2005. [CrossRef]

40. Kwak, M.-K.; Liu, R.; Kang, S.-O. Antimicrobial Activity of Cyclic Dipeptides Produced by Lactobacillus plantarum LBP-K10 against Multidrug-Resistant Bacteria, Pathogenic Fungi, and Influenza A Virus. Food Control 2018, 85, 223-234. [CrossRef]

41. Le, N.T.T.; Bach, L.G.; Nguyen, D.C.; Le, T.H.X.; Pham, K.H.; Nguyen, D.H.; Hoang Thi, T.T. Evaluation of Factors Affecting Antimicrobial Activity of Bacteriocin from Lactobacillus plantarum Microencapsulated in Alginate-Gelatin Capsules and Its Application on Pork Meat as a Bio-Preservative. Int. J. Environ. Res. Public. Health 2019, 16, 1017. [CrossRef]

42. Chen, C.; Cao, Z.; Li, J.; Tao, C.; Feng, Y.; Han, Y. A Novel Endophytic Strain of Lactobacillus plantarum CM-3 with Antagonistic Activity against Botrytis cinerea on Strawberry Fruit. Biol. Control 2020, 148, 104306. [CrossRef]

43. Zhang, Y.; Gao, Y.; Zheng, Z.; Meng, X.; Cai, Y.; Liu, J.; Hu, Y.; Yan, S.; Wang, X. A Microbial Ecosystem: Agricultural Jiaosu Achieves Effective and Lasting Antifungal Activity against Botrytis cinerea. AMB Express 2020, 10, 216. [CrossRef] [PubMed]

44. Khodaei, D.; Hamidi-Esfahani, Z. Influence of Bioactive Edible Coatings Loaded with Lactobacillus plantarum on Physicochemical Properties of Fresh Strawberries. Postharvest Biol. Technol. 2019, 156, 110944. [CrossRef]

45. De Giani, A.; Bovio, F.; Forcella, M.; Fusi, P.; Sello, G.; Di Gennaro, P. Identification of a Bacteriocin-like Compound from Lactobacillus plantarum with Antimicrobial Activity and Effects on Normal and Cancerogenic Human Intestinal Cells. AMB Express 2019, 9, 88. [CrossRef]

46. Kim, S.W.; Kang, S.I.; Shin, D.H.; Oh, S.Y.; Lee, C.W.; Yang, Y.; Son, Y.K.; Yang, H.-S.; Lee, B.-H.; An, H.-J.; et al. Potential of Cell-Free Supernatant from Lactobacillus plantarum NIBR97, Including Novel Bacteriocins, as a Natural Alternative to Chemical Disinfectants. Pharmaceuticals 2020, 13, 266. [CrossRef]

47. Ołdak, A.; Zielińska, D.; Łepecka, A.; Długosz, E.; Kołożyn-Krajewska, D. Lactobacillus plantarum Strains Isolated from Polish Regional Cheeses Exhibit Anti-Staphylococcal Activity and Selected Probiotic Properties. Probiotics Antimicrob. Proteins 2020, 12, 1025-1038. [CrossRef] [PubMed]

48. Salari, S.; Almani, P.G.N. Antifungal Effects of Lactobacillus acidophilus and Lactobacillus plantarum against Different Oral Candida Species Isolated from HIV/ AIDS Patients: An in Vitro Study. J. Oral Microbiol. 2020, 12, 1769386. [CrossRef] [PubMed]

49. Deepthi, B.V.; Rao, K.P.; Chennapa, G.; Naik, M.K.; Chandrashekara, K.T.; Sreenivasa, M.Y. Antifungal Attributes of Lactobacillus plantarum MYS6 against Fumonisin Producing Fusarium proliferatum Associated with Poultry Feeds. PLoS ONE 2016, 11, e0155122. [CrossRef]

50. Xie, C.; Wang, H.; Deng, S.; Xu, X.-L. The Inhibition of Cell-Free Supernatant of Lactobacillus plantarum on Production of Putrescine and Cadaverine by Four Amine-Positive Bacteria in Vitro. LWT Food Sci. Technol. 2016, 67, 106-111. [CrossRef]

51. Ahmad Rather, I.; Seo, B.J.; Rejish Kumar, V.J.; Choi, U.-H.; Choi, K.-H.; Lim, J.H.; Park, Y.-H. Isolation and Characterization of a Proteinaceous Antifungal Compound from Lactobacillus plantarum YML007 and Its Application as a Food Preservative. Lett. Appl. Microbiol. 2013, 57, 69-76. [CrossRef] [PubMed]

52. George-Okafor, U.; Ozoani, U.; Tasie, F.; Mba-Omeje, K. The Efficacy of Cell-Free Supernatants from Lactobacillus plantarum Cs and Lactobacillus acidophilus ATCC 314 for the Preservation of Home-Processed Tomato-Paste. Sci. Afr. 2020, 8, e00395. [CrossRef]

53. Daranas, N.; Roselló, G.; Cabrefiga, J.; Donati, I.; Francés, J.; Badosa, E.; Spinelli, F.; Montesinos, E.; Bonaterra, A. Biological Control of Bacterial Plant Diseases with Lactobacillus plantarum Strains Selected for Their Broad-spectrum Activity. Ann. Appl. Biol. 2019, 174, 92-105. [CrossRef] [PubMed]

54. Wang, H.; Yan, H.; Shin, J.; Huang, L.; Zhang, H.; Qi, W. Activity against Plant Pathogenic Fungi of Lactobacillus plantarum IMAU10014 Isolated from Xinjiang Koumiss in China. Ann. Microbiol. 2011, 61, 879-885. [CrossRef]

55. Magnusson, J.; Ström, K.; Roos, S.; Sjögren, J.; Schnürer, J. Broad and Complex Antifungal Activity among Environmental Isolates of Lactic Acid Bacteria. FEMS Microbiol. Lett. 2003, 219, 129-135. [CrossRef]

56. Dalié, D.K.D.; Deschamps, A.M.; Richard-Forget, F. Lactic Acid Bacteria-Potential for Control of Mold Growth and Mycotoxins: A Review. Food Control 2010, 21, 370-380. [CrossRef]

57. Gajbhiye, M.H.; Kapadnis, B.P. Antifungal-Activity-Producing Lactic Acid Bacteria as Biocontrol Agents in Plants. Biocontrol Sci. Technol. 2016, 26, 1451-1470. [CrossRef]

58. Lipińska, L.; Klewicki, R.; Sójka, M.; Bonikowski, R.; Żyżelewicz, D.; Kołodziejczyk, K.; Klewicka, E. Antifungal Activity of Lactobacillus pentosus ŁOCK 0979 in the Presence of Polyols and Galactosyl-Polyols. Probiotics Antimicrob. Proteins 2018, 10, 186-200. [CrossRef]

59. Lipińska, L.; Klewicki, R.; Klewicka, E.; Kołodziejczyk, K.; Sójka, M.; Nowak, A. Antifungal Activity of Lactobacillus Sp. Bacteria in the Presence of Xylitol and Galactosyl-Xylitol. BioMed Res. Int. 2016, 5897486. [CrossRef]

60. Lipinska-Zubrycka, L.; Klewicki, R.; Sojka, M.; Bonikowski, R.; Milczarek, A.; Klewicka, E. Anticandidal Activity of Lactobacillus Spp. in the Presence of Galactosyl Polyols. Microbiol. Res. 2020, 240, 126540. [CrossRef]

61. Siedler, S.; Balti, R.; Neves, A.R. Bioprotective Mechanisms of Lactic Acid Bacteria against Fungal Spoilage of Food. Curr. Opin. Biotechnol. 2019, 56, 138-146. [CrossRef]

62. Yoo, J.A.; Lim, Y.M.; Yoon, M.H. Production and Antifungal Effect of 3-Phenyllactic Acid (PLA) by Lactic Acid Bacteria. J. Appl. Biol. Chem. 2016, 59, 173-178. [CrossRef] 
63. Lemos, W.J.F., Jr.; Bovo, B.; Nadai, C.; Crosato, G.; Carlot, M.; Favaron, F.; Giacomini, A.; Corich, V. Biocontrol Ability and Action Mechanism of Starmerella bacillaris (Synonym Candida zemplinina) Isolated from Wine Musts against Gray Mold Disease Agent Botrytis Cinerea on Grape and Their Effects on Alcoholic Fermentation. Front. Microbiol. 2016, 7, 1249. [CrossRef]

64. Qin, X.; Xiao, H.; Cheng, X.; Zhou, H.; Si, L. Hanseniaspora uvarum Prolongs Shelf Life of Strawberry via Volatile Production. Food Microbiol. 2017, 63, 205-212. [CrossRef] [PubMed]

65. Ruiz-Moyano, S.; Hernández, A.; Galvan, A.I.; Córdoba, M.G.; Casquete, R.; Serradilla, M.J.; Martín, A. Selection and Application of Antifungal VOCs-Producing Yeasts as Biocontrol Agents of Grey Mold in Fruits. Food Microbiol. 2020, 92, 103556. [CrossRef]

66. Zudaire, L.; Viñas, I.; Plaza, L.; Iglesias, M.B.; Abadias, M.; Aguiló-Aguayo, I. Evaluation of Postharvest Calcium Treatment and Biopreservation with Lactobacillus rhamnosus GG on the Quality of Fresh-Cut 'Conference' Pears. J. Sci. Food Agric. 2018, 98, 4978-4987. [CrossRef]

67. Abadias, M.; Altisent, R.; Usall, J.; Torres, R.; Oliveira, M.; Viñas, I. Biopreservation of Fresh-Cut Melon Using the Strain Pseudomonas graminis CPA-7. Postharvest Biol. Technol. 2014, 96, 69-77. [CrossRef]

68. Russo, P.; Peña, N.; de Chiara, M.L.V.; Amodio, M.L.; Colelli, G.; Spano, G. Probiotic Lactic Acid Bacteria for the Production of Multifunctional Fresh-Cut Cantaloupe. Food Res. Int. 2015, 77, 762-772. [CrossRef]

69. Siroli, L.; Patrignani, F.; Serrazanetti, D.I.; Gardini, F.; Lanciotti, R. Innovative Strategies Based on the Use of Bio-Control Agents to Improve the Safety, Shelf-Life and Quality of Minimally Processed Fruits and Vegetables. Trends Food Sci. Technol. 2015, 46, 302-310. [CrossRef] 